\title{
Minimally Invasive Esophagectomy in the Elderly
}

\author{
Shailesh Puntambekar • Rahul Kenawadekar • Archit Pandit • \\ Akshay Nadkarni • Saurabh Joshi • Geetanjali Agarwal • \\ Nasir Ahmad Bhat • Jainul Malik • Sunil Reddy
}

Received: 27 March 2013 / Accepted: 14 August 2013 /Published online: 24 August 2013

(C) Indian Association of Surgical Oncology 2013

\begin{abstract}
Objective A retrospective analysis of a prospectively maintained database to evaluate our experience in elderly patients ( $>70$ years) undergoing Thoracolaparoscopic esophagectomy for cancer oesophagus. To ascertain whether age, is a limiting factor for patients undergoing minimally invasive esophagectomy.

Methods All Patients above 70 years of age, referred to the Gastro-esophageal clinic were included in the study. Tumours were staged as per AJCC 6th ed. 2002. Patients diagnosed with T1/2/3, N0/1 lesion of the mid/lower oesophagus (Infra Azygous) and type I and II Gastro esophageal junction tumours were included in the study. Patients with ASA grade IV were excluded. All patients who underwent Thoracolaparoscopic
\end{abstract}

S. Puntambekar $(\bowtie) \cdot$ R. Kenawadekar · A. Pandit • A. Nadkarni • S. Joshi $\cdot$ G. Agarwal $\cdot$ N. A. Bhat $\cdot$ J. Malik $\cdot$ S. Reddy

Department of Minimal Access Surgery, Galaxy Care Laparoscopic Institute, Karve Road, Pune, India

e-mail: shase63@gmail.com

R. Kenawadekar

e-mail: dr_rahuldk@yahoo.co.in

A. Pandit

e-mail: drarchitpandit@yahoo.co.in

A. Nadkarni

e-mail: dr.rahuldk@gmail.com

S. Joshi

e-mail: snjo2006@yahoo.co.in

G. Agarwal

e-mail: geetanjali_agarwal@hotmail.com

N. A. Bhat

e-mail: sufismed@gmail.com

J. Malik

e-mail: jainulmalik@yahoo.com

S. Reddy

e-mail: drsunilreddy@ymail.com esophagectomy from January 2009 till January 2012 were evaluated for their perioperative outcomes.

Results Sixty eight patients underwent Minimal Invasive esophagectomy from January 2009 to January 2012. There were 45 males and 23 females. The average age in elderly group was $75.76 \pm 5.96$ years (range 70 to 91 ). Mean operative time was $178.84 \pm 65.26$ min, mean blood loss $143.84 \mathrm{ml}$ (range 32 $450 \mathrm{ml}$ ), mean ICU stay 3.84 days(range $2-11$ days) and mean hospital stay was 12.76 days(range 8-21 days). Pneumonia and Cardiac related complications occurred in $10.30 \%$ and $1.47 \%$ patients respectively. None of the procedures required conversion to open thoracotomy.

Conclusions Thoracolaparoscopic esophagectomy is feasible and surgically safe in elderly patients with low morbidity and mortality. Thus age of a patient should not be considered a limiting factor.

Ultramini Abstract This is an original article about our experience of thoracolaparoscopic esophagectomy for cancer esophagus in elderly patients. After analyzing the data we feel that age of the patient cannot be a truly limiting factor for patient diagnosed of esophageal cancer to undergo minimally invasive esophagectomy.

Keywords Esopphageal cancer · Minimal invasive esophagectomy $\cdot$ Elderly $\cdot$ Laparoscopy $\cdot$ Thoracosopy

\section{Introduction}

Esophageal cancer is a disease of the elderly with a median age of 60 years $[1,2]$. Although there have been significant advances in other modalities of treatment, surgery still remains the only chance for cure[3, 4]. Higher post-operative morbidity and mortality rates after open esophagectomy in the elderly are well recognized and advanced age has been considered a significant risk factor. Esophagectomy is a high risk procedure 
because of the associated pulmonary complications with a reported mortality of 2-23\% [1, 3, 5] Tables $1,2,3,4$ and 5 .

Besides the increasing incidence of esophageal carcinoma, the rising life expectancy in the general population is responsible for a relatively large number of elderly patients presenting with esophageal cancer ${ }^{1}$ Moreover, this group of patients often have considerable co morbidities which include diabetes, pulmonary, cardiovascular diseases and obesity [6, 7] resulting in reflection of a poor postoperative outcome [8-13]. There is lack of evidence regarding the appropriate surgical treatment of esophageal cancer in the elderly population. Some authors[14-18] propose a transhiatal procedure for better short-term outcome with less morbidity, while others favour non-surgical options such as endomucosal resection, endoscopic ablative therapies and definite chemo-radiation. Frequently, due consideration for radical surgical resection may not be given because of the concerns with regard to the morbidity of open esophagectomy in elderly. A minimally invasive approach for Esophagectomy was originally described by Cuschieri et al. [19]. Since then minimally invasive esophagectomy (MIE) has been performed with increasing frequency. MIE has the potential to lower the morbidity of open operation, allow quicker return to normal function and offer a chance of cure. However, limited data exist regarding the role of MIE in this subset of population. To address this question we conducted a retrospective study to evaluate the feasibility, oncologic clearance and perioperative outcomes of MIE in the elderly population.

Table 1 Patient and tumor characteristics

\begin{tabular}{ll}
\hline & $\begin{array}{l}\text { Age } \geq 70 \text { patients } \\
N=68\end{array}$ \\
\hline Age (mean/Median) (Range) Yrs. & $75.76 / 77(70-91)$ \\
Male/Female & $45 / 23$ \\
BMI, Kg/m ${ }^{2}$ Mean & 26.2 \\
Albumin, mg/dl, Median (Range) & $2.9 / 2.8(2.1-4.6)$ \\
ASA Grade 1 & $08(11 \%)$ \\
ASA Grade 2 & $22(32.3 \%)$ \\
ASA Grade 3 & $38(55.8 \%)$ \\
Site & \\
Middle third & $51(75)$ \\
Lower third & $17(25)$ \\
Histological type & \\
Squamous carcinoma & $57(84)$ \\
Adenocarcinoma & $09(13)$ \\
G.I.S.T & $01(1.4)$ \\
Neuroendocrine tumour & $01(1.4)$ \\
Clinical+radiological pre operative staging & \\
I & 21 \\
II & 47 \\
Preoperative endoscopic NG tube insertion & 54 \\
\hline
\end{tabular}

Table 2 Pre-existing co-morbid conditions

\begin{tabular}{ll}
\hline COPD/Emphysema & $15(22 \%)$ \\
\hline Diabetes Mellitus & $18(26.4 \%)$ \\
Hypertension & $26(38 \%)$ \\
Coronary artery disease or H/o any cardiac events & $14(20.5 \%)$ \\
H/o Tuberculosis & $22(30 \%)$ \\
\hline
\end{tabular}

\section{Materials and Methods}

Methods All patients undergoing MIE at Galaxy care laparoscopy institute from January 2009 to January 2012 were included in the study. Institutional Review Board (IRB) permission was obtained. We used a Board approved database designed to assess outcomes after MIE. Data collected included demographics profile, co-morbidities, Pulmonary function test (PFT), laboratory and radiographic studies, operative time, blood loss, conversion to thoracotomy, histologic diagnosis, pathologic stage, R0 resection, total number of harvested lymph nodes, tumour specific variables, length of stay and perioperative morbidity like pulmonary complications and cardiac events. A query was ran on a prospectively maintained database to look for patients more than 70 years of age who underwent minimally invasive Thoracolaparoscopic esophagectomy (excluding Robotic esophagectomy) with T1/ 2/3, N0/1 lesions. Data was collected for analysis of all patients who met the aforementioned criteria's. Perioperative mortality defined as within 30 days of discharge were noted. W.H.O defines the age of elderly as $>65$ years however we had a substantial no. of patients above the age of 70 hence defined in our study.

Table 3 Surgical outcome

\begin{tabular}{ll}
\hline & $\begin{array}{l}\text { Age } \geq 70 \text { patients } \\
\text { Mean, (Range) }\end{array}$ \\
\hline $\begin{array}{l}\text { Mean Blood Loss (ml), (Range) } \\
\text { Time for Thoracoscopic Esophageal }\end{array} \quad 143.84(32-450)$ \\
$\quad$ Mobilization (min), Mean & $67.26(45-110)$ \\
Total Mean Operative time (min) & $178.84(90-240)$ \\
ICU stay, days, Mean & $3.84(2-11)$ \\
Hospital stay, days, Mean & $12.76(8-21)$ \\
No. of patients developing major & $13(20.6 \%)$ \\
$\quad$ post-operative complications & \\
$\quad$ No. of patients developing Minor & $7(10.3 \%)$ \\
Ro rest-operative complications & $66(97 \%)$ \\
Lymph nodes harvested Mean, Median (Range) & $15.15,16(9-23)$ \\
Positive Circumferential margins & 2 \\
\hline
\end{tabular}


Table 4 Postoperative complications

Major complications

\begin{tabular}{lc}
\hline Tracheal Tear & 01 \\
Pneumonia & $06(10.3 \%)$ \\
Anastomotic Leak & $06(10.3 \%)$ \\
Hoarseness of voice & $3 / 68(4.4 \%)$ \\
Myocardial infarction & 01 \\
Chylous leak & 00 \\
Mediastinitis & 02 \\
Minor complications & \\
Wound infections & $06(10.3 \%)$ \\
Cardiac Arrhythmia & $11(17 \%)$ \\
Mediastinitis sec. to Anastomotic leak & $02(3.8 \%)$ \\
30 day perioperative mortality & $03(4.4 \%)$ \\
\hline
\end{tabular}

Pre-Operative Evaluation

All patients underwent thorough Loco regional and metastatic evaluation with help of esophagogastroscopy and computed tomography of chest and abdomen. Bronchoscopy was routinely performed for mid esophageal growths with close proximity to carina and bronchus. Endoscopic ultrasound and PET CT were not done routinely due to financial constraints. Operability was assessed by a team of anaesthetist, pulmonologist and physician. Pulmonary function tests and arterial blood gas analysis were routinely performed for all cases. 2-D echocardiography was done when required. Patients with high pulmonary risk as defined by FEV1 $<50 \%$ with or without Hypercarbia were excluded from the study. Staging was performed based on American Joint Commission on Cancer (AJCC) 6th ed. 2002[20]. Patients with T1/2/3 with N0/1 lesions underwent minimally invasive esophagectomy. Patients with T4 lesions underwent neoadjuvant chemotherapy/ radiotherapy were downstaged and hence also included in the study. GE junction tumours were staged and treatment protocol followed like in esophageal cancers.

Operative Outcomes

As an institutional protocol all patients underwent transthoracic esophageal mobilization in prone position, with Laparoscopic gastric mobilization and two field Lymphadenectomy. A $6 \mathrm{~cm}$ vertical midline incision was taken for creating an extracorporeal gastric tube. Azygous vein was preserved in all cases. None of patients underwent Pyloromyotomy. Esophago-gastric end to side double layer anastomosis was performed with 3-0 Vicryl in the left neck with a $4 \mathrm{~cm}$ supraclavicular incision. Patients were evaluated for their preoperative, intraoperative and postoperative outcomes.

\section{Post-Operative Details}

Patients were kept in ICU till they were extubated, hemodynamically stable and off inotropic or ventilatory supports postoperatively, patients received enteral nutrition through the jejunostomy feeding tube from postoperative day 2 . Those who required only oxygen support by mask or nasal prongs were shifted out of ICU. Postoperatively intercostal drains were removed when there was adequate lung expansion on x-ray. Water soluble contrast swallow was performed on postoperative day 10 in those patients who did not have any signs of anastomotic leak. Two weeks later all the patients were evaluated by a joint team of surgical, medical and radiation oncologist to plan adjuvant therapy according to the final histopathology report.
Table 5 Comparison with other studies

\begin{tabular}{|c|c|c|c|c|c|c|}
\hline & $\begin{array}{l}\text { Our Present } \\
\text { Series }\end{array}$ & $\begin{array}{l}\text { Leuketich } \\
\text { et.al. [39] } \\
N=481\end{array}$ & $\begin{array}{l}\text { Berger } \\
\text { et.al. } \\
{[34]} \\
N=65\end{array}$ & $\begin{array}{l}\text { Smither's } \\
\text { et. al } \\
{[28]}\end{array}$ & $\begin{array}{l}\text { Dexter } \\
\text { et. al } \\
{[29]}\end{array}$ & $\begin{array}{l}\text { Puntambekar } \\
\text { et.al (Lateral } \\
\text { position) } \\
{[27] N=112}\end{array}$ \\
\hline Mean age & 75.76 & 65 & 61 & 61 & 62 & 54 \\
\hline Conversion $\%$ & $0 \%$ & $5 \%$ & $9 \%$ & $7 \%$ & $4.2 \%$ & $1.7 \%$ \\
\hline Recurrent L.N palsy & $3 / 68(4.4 \%)$ & $8 \%$ & - & $5 \%$ & $36 \%$ & $3.6 \%$ \\
\hline $\begin{array}{l}\text { Respiratory } \\
\text { complications }\end{array}$ & $10.3 \%$ & $10 \%$ & $15-20 \%$ & $27 \%$ & $59 \%$ & $7.2 \%$ \\
\hline Anastomotic leak & $10.3 \%$ & $5 \%$ & $14 \%$ & $4 \%$ & $9 \%$ & $2.7 \%$ \\
\hline Chyle leak & $0 \%$ & - & - & $2.4 \%$ & $9 \%$ & $0 \%$ \\
\hline $\begin{array}{l}\text { Total LN harvested } \\
\text { (Mean) }\end{array}$ & 15.1 & 19 & 20 & - & 13 & 23 \\
\hline Mean blood loss & $143 \mathrm{ml}$ & - & $182 \mathrm{ml}$ & 165 & - & 200 \\
\hline $\begin{array}{l}\text { Mean operating time } \\
\text { (total) }\end{array}$ & 179 & - & - & 299 & - & 185 \\
\hline $\begin{array}{l}\text { Mean thoracic operating } \\
\text { time }\end{array}$ & 67 & - & - & 104 & 183 & 85 \\
\hline Mortality (\%) & $4.4 \%$ & $2.5 \%$ & $7.7 \%$ & $8 \%$ & $14 \%$ & $2.7 \%$ \\
\hline
\end{tabular}




\section{Results}

263 operable patients underwent minimally invasive esophagectomy from January 2009 to January 2012. 79 patients underwent Hybrid Robotic Transthoracic esophagectomy. The decision to do robotic surgery was based on financial and not scientific basis. Sixty eight (68) out of 184 patients who underwent Thoracolaparoscopic esophagectomy were $>70$ years of age.

All patients underwent Thoracoscopic esophageal mobilization in prone position followed by Gastric mobilization with two field lymphadenectomy followed by Esophago-gastric hand sewn cervical anastomosis. Stomach tube was used as conduit in all patients. Pyloromyotomy or pyloroplasty was performed in none. Feeding jejunostomy was performed in all the patients. None of the patients required conversion to open thoracotomy.

The mean age in elderly was 75.76 years (range 70-91 years). The indications for surgery included 57 squamous, 09 adenocarcinomas and 2 miscellaneous. Mid thoracic oesophagus was the most common site of tumour location. $64 \%$ of patients with stage III(node positive) underwent short course radiotherapy [post operatively] [41]. None of the patients with T3 lesions underwent neoadjuvant chemotherapy or concurrent chemo radiotherapy (CRT). Two patients with T4 lesions underwent pre-operative chemoradiation and were downstaged. $55 \%$ of patients were ASA grade III with hypertension, COPD and Diabetes mellitus being the most common pre-operative co-morbidity. Two patients had R1 resection. Both these patients had had undergone preoperative RT for $\mathrm{T} 4$ lesions as mentioned previousy.

\section{Discussion}

Surgical treatment for esophageal cancer has undergone a significant change. The traditional open surgical transthoracic and transhiatal oesophagectomies is associated with a relatively high morbidity of up to $80 \%$ and 5-20\% mortality even when performed by experienced surgeons [16]. A recent Study by Tanja $\mathrm{M}$ Cijs et al. has concluded that there is increase in non surgical complications and operative and in hospital mortality following esophageal resection in elderly patients. They further state that in elderly patients with pre existing pulmonary disease thoracoabdominal resections should be avoided [21]. This led to popularization of alternate modalities of treatment ranging from transhiatal esophagectomy to photodynamic therapy. Our study indicates that surgery not only offers good quality swallowing but also offers the chance of cure even in the advanced stages. Thus if surgery is offered with curative intent it is mandatory to keep the morbidity and mortality within the acceptable limits. MIS has a potential to decrease the morbidity associated with thoracoabdominal surgery. Therefore MIS esophageal resection may be offered to even those elderly patients with co-morbidities [22-26].

Number of studies have reported their results of minimally invasive esophagectomy and most have shown promising results with respect to low post-operative complication rates and morbidity [27-32]. However, none of the studies address if minimally invasive esophagectomy can be performed safely in the elderly. Mean age in most of such studies is in the range of 61-65 years [31,32]. Mean age of the cohort in our study is 75.76 years. This is a preliminary data to assess the safety and feasibility of minimally invasive esophagectomy in the elderly. We have addressed only the perioperative results in this study. We have already started a prospective study to compare the results with younger patients which will be reported once the study is complete.

Various studies have shown the benefits of minimally invasive esophagectomy over open esophagectomy with respect to blood loss, nodal yield, safety and reduced morbidity [28-33]. However, age still remains a relative contraindication for esophagectomy. One of the main outcome criteria that limit esophagectomy in elderly age group is pulmonary complications. Pneumonia, the most frequently encountered pulmonary complication. All the male patients in our study were either smokers or tobacco chewers and $30 \%$ of had been treated with antituberculous drugs. Inspite of these factors pulmonary complications were seen in $10 \%$ of our patients. This is comparable to that of Luketich et al. [39]. with $8 \%$ of patients developing pneumonia. Other studies report respiratory complications ranging from 10 to $27 \%[27,28]$ in spite of the mean age of the cohort of around 61 years. Dexter et. al [29] reported pulmonary complications in $>50 \%$ of patients though the author had taken complications other than pneumonia, like atelectasis and pleural effusion also into consideration. Our previously published series of Minimally invasive esophagectomy in lateral position of 112 patients showed pulmonary complications in 7-8\% of patients but the mean age of patients being 54 (Range: 25-78) [27]. Minimal difference of respiratory complication in our study when compared to others is possibly because of the high mean age of the cohort which was well below 70 in other studies.

Total blood loss and mean operating time was comparable to other studies [34]. The time taken for relatively lower thoracic operating time is probably the result of our institution being one of the high volume centres with $>100$ oesophagectomies being performed in a year. Reduced thoracic operating time could as well be the reason for comparable if not lower pulmonary complications when compared to other studies.

Recurrent laryngeal nerve injury has been reported with incidence of 7-33\% after Thoracoscopic esophagectomy [29]. In our series the incidence was 3/68(4.4) the recurrent nerve palsy was transient. Low R.L N palsy could be attributed to the two field infra-Azygous lymphatic dissection that we perform. The Mean nodal harvest was 15 . This is also comparable to that mentioned in the other studies [28, 29, 33, 35]. Only two patients had R1 resection while in others we had R0. Suffice to say that we did not compromise on the oncological clearance due to the age of the patients. 
The incidence of anastomotic leak observed was $10.3 \%$. There is no study which compares the anastomotic leaks in the elderly. However, one of the largest series of open Mc Kneown esophagectomy by Swanson and colleagues [35] reported anastomotic leak rates of up to $8 \%$. Other series of minimally invasive esophagectomy report leak rates ranging from 4 to $11 \%[27,28,32]$. The incidence of anastomotic leak rates in our study is comparable to all the mentioned series of esophagectomy [36-38]. These findings should be interpreted carefully as the mean age in these studies was around 60 years. In our future study we will be analysing age as an independent factor for anastomotic healing.

Mean ICU and hospital stay in our study was 3.8 and 12.7 days. Luketich [39] in 2003 reported Median ICU and Hospital stay of 1 and 7 days respectively. Other studies likewise report in the range of 2 to 5 days and 9-18 days respectively, comparable to our results $[33,36]$.

There were three perioperative mortality in our study. Two Patients developed signs and symptoms suggestive of mediastinitis secondary to an anastomotic leak in the neck and one patient developed a massive Myocardial infarction. The mortality rate of $4.4 \%$ is observed in our study. Luketich et al. reported 30 day perioperative mortality of $2.5 \%(n=481)$ [39]. A population based national study comprising 1155 patients reported $4 \%$ mortality rate [40]. While other studies report mortality rates ranging from 7 to $14 \%[27,28,32,39,40]$. This relatively low mortality could be attributed to the less no. of patients in our study.

\section{Conclusion}

Thoracolaparoscopic esophagectomy is feasible and surgically safe in elderly patients. This results in faster postoperative recovery because of fewer pulmonary and wound related complications. These perioperative outcomes are comparable to those reported in the other studies of VATS. Thus age of a patient should not be a limiting factor for deciding need of surgery in elderly patients. Given the retrospective nature of our study the results needs to be confirmed by randomised control trials.

Conflicts of Interests All authors no conflicts of interest or financial ties to disclose.

\section{References}

1. Enzinger PC (2003) Esophageal cancer. N Engl J Med 349:2241-52

2. Scott Bolton J (2001) Esophagectomy for adenocarcinoma in patients 45 years of age and younger. J Gastrointest Surg 5:620-5

3. Stein HJ, Siewert JR (2004) Improved prognosis of resected esophageal cancer. World J Surg 28:520-5
4. Pennathur A, Luketich JD (2008) Resection for esophageal cancer: strategies for optimal management. Ann Thorac Surg 85:S751-6

5. Sauvanet A, Mariette C, Thomas P, Lozac'h P, Segol P, Tiret E et al (2005) Mortality and morbidity after resection for adenocarcinoma of the gastroesophageal junction: predictive factors. J Am Coll Surg 201:253-62

6. Bollschweiler E (2000) Preoperative risk analysis in patients with adenocarcinoma or squamous cell carcinoma of the oesophagus. Brit J Surg 87:1106-10

7. Abunasra H, Lewis S, Beggs L, Duffy J, Beggs D, Morgan E (2005) Predictors of operative death after oesophagectomy for carcinoma. $\mathrm{Br}$ J Surg 92:1029-33

8. Ma JY, Wu Z, Wang Y, Zhao YF, Liu LX, Kou YL et al (2006) Clinicopathologic characteristics of esophagectomy for esophageal carcinoma in elderly patients. World J Gastroenterol 12:1296-9

9. Moskovitz AH, Rizk NP, Venkatraman E, Bains MS, Flores RM, Park BJ et al (2006) Mortality increases for octogenarians undergoing esophagogastrectomy for esophageal cancer. Ann Thorac Surg 82:2031-6

10. Poon RT, Law SY, Chu KM, Branicki FJ, Wong J (1998) Esophagectomy for carcinoma of the esophagus in the elderly: results of current surgical management. Ann Surg 227:357-64

11. Sabel MS, Smith JL, Nava HR, Mollen K, Douglass HO, Gibbs JF (2002) Esophageal resection for carcinoma in patients older than 70 years. Ann Surg Oncol 9:210-4

12. Internullo E, Moons J, Nafteux P, Coosemans W, Decker G, De LP et al (2008) Outcome after esophagectomy for cancer of the esophagus and GEJ in patients aged over 75 years. Eur J Cardiothorac Surg 33:1096-104

13. Peyre CG, Hagen JA, DeMeester SR, Altorki NK, Ancona E, Griffin SM et al (2008) The number of lymph nodes removed predicts survival in esophageal cancer: an international study on the impact of extent of surgical resection. Ann Surg 248:549-56

14. Lerut T, Nafteux P, Moons J, Coosemans W, Decker G, De Leyn P et al (2004) Three-field lymphadenectomy for carcinoma of the esophagus and gastroesophageal junction in $174 \mathrm{R} 0$ resections: Impact on staging, disease-free survival, and outcome: a plea for adaptation of TNM classification in upper-half esophageal carcinoma. Ann Surg 240:962-72

15. Davies AR, Forshaw MJ, Khan AA, Noorani AS, Patel VM, Strauss DC et al (2008) Transhiatal esophagectomy in a high volume institution. World J Surg Oncol 6:88

16. Bailey SH, Bull DA et al (2003) Outcomes after esophagectomy: A ten year retrospective cohort. Ann Thorac Surg 75:217-22

17. DePaula AL, Hashiba K, Ferreira EA et al (1996) Transhiatal approach for esophagectomy. In: Tooli J, Gossot D, Hunter JG (eds) Endosurgery. Churchill Livingstone, New York, pp 293-9

18. Goldminc M, Maddern G, LePrise E et al (1993) Oesophagectomy by a transhiatal approach or thoracotomy: A prospective randomized trial. Br J Surg 80:367-370

19. Cuschieri A (1994) Thoracoscopic subtotal oesophagectomy. Endosc Surg Allied Technol 2:21-25

20. American Joint Commission on Cancer (2002) AJCC cancer staging manual, 6th edn. Springer Verlag, New York

21. Cijs TM, Verhoef C, Steyerberg EW, Koppert LB, Khe Tran TC, Wijnhoven BPL, Tilanus HW, de Jonge J (2010) Outcome of esophagectoy for cancer in elderly patients. Ann Thorac Surg 90:900-7

22. Ma JY, Wu Z, Wang Y, Zhao YF, Liu LX, Kou YL, Zhou QH (2006) Clinicopathologic characteristics of esophagectomy for esophageal carcinoma in elderly patients. World J Gastroenterol 12(8):1296-1299

23. Ruol A, Portale G, Zaninotto G, Cagol M, Cavallin F, Castoro C et al (2007) Results of esophagectomy for esophageal cancer in elderly patients: age has little influence on outcome and survival. J Thorac Cardiovasc Surg 133:1186-92

24. Internullo E, Moons J, Nafteux P, Coosemans W, Decker G, De LP et al (2008) Outcome after esophagectomy for cancer of the esophagus and GEJ in patients aged over 75 years. Eur J Cardiothoracic Surg 33:1096-104

25. Pultrum BB, Bosch DJ, Nijsten MW, Rodgers MG, Groen H, Slaets JP, Plukker JT (2010) Extended esophagectomy in elderly patients 
with esophageal cancer: Minor effect of age alone in determining the postoperative course and survival. Ann Surg Oncol 17(6):1572-80, Epub 2010 Feb 24

26. Perry Y, Fernando HC, Buenaventura PO, Christie NA, Luketich JD (2002) Minimally invasive esophagectomy in the elderly. JSLS 6(4): 299-304

27. Puntambekar SP, Agarwal GA, Joshi SN, Rayate NV, Sathe RM, Patil AM. Thoracolaparoscopy in the lateral position for esophageal cancer: The experience of a single institution with 112 consecutive patients. Surg Endosc. 2010 Mar 5.

28. Cuschieri A, Shimi S, Banting S (1992) Endoscopic oesophagectomy through a right thoracoscopic approach. J R Coll Surg Edinb 37:7-11

29. Dexter SP, Martin IG, McMahon MJ (1996) Radical thoracoscopic esophagectomy for cancer. Surg Endosc 10:147-151

30. Smithers BM, Gotley DC, McEwan D, Martin I, Bessell J, Doyle L (2001) Thoracoscopic mobilization of the esophagus. A 6 year experience. Surg Endosc 15:176-182

31. Law S, Fok M, Chu KM, Wong J (1997) Thoracoscopic esophagectomy for esophageal cancer. Surgery 122:8-14

32. Nguyen NT, Follette DM, Wolfe BM, Schneider PD, Roberts P, Goodnight JE (2000) Comparison of minimally invasive esophagectomy with transthoracic and transhiatal esophagectomy. Arch Surg 135:920-925

33. Lazzarino AI, Nagpal K, Bottle A et al (2010) Open versus minimally invasive esophagectomy: Trends of utilization and associated outcomes in England. Ann Surg 252:292-298
34. Berger AC, Bloomenthal A, Weksler B et al (2011) Oncologic efficacy is not compromised, and may be improved with minimally invasive esophagectomy. J Am Coll Surg 212:560-568

35. Swanson SJ, Batirel HF, Bueno R et al (2001) Transthoracic esophagectomy with radical mediastinal and abdominal lymph node dissection and cervical esophagogastrostomy for esophageal carcinoma. Ann Thorac Surg 72:1918-1924

36. Pham TH, Perry KA, Dolan JP et al (2010) Comparison of perioperative outcomes after combined thoracoscopic-laparoscopic esophagectomy and open Ivor-Lewis esophagectomy. Am J Surg 199:594-598

37. Gemmill EH, McCulloch P (2007) Systematic review of minimally invasive resection for gastro-oesophageal cancer. Br J Surg 94:1461-1467

38. Decker G, Coosemans W, De Leyn P, Decaluwé H, Nafteux P, Van Raemdonck D, Lerut T (2009) Minimally invasive esophagectomy for cancer. Eur J Cardiothorac Surg 35:13-20, discussion 20-21

39. Luketich JD, Pennathur A, Awais O et al (2012) Outcomes after minimally invasive esophagectomy, review of over 1000 patients. Ann Surg 256:95-103

40. Mamidanna R, Bottle A, Aylin P et al (2012) Short-Term Outcomes Following Open Versus Minimally Invasive Esophagectomy for Cancer in England, A Population-Based National Study. Ann Surg 255:197-203

41. Yaping X, Jinshi L, Xianghui D, Xiaojiang S, Yuanda Z, Jianxiang C, Bo L, Wei L, Hao J, Weimin M (2013) Prognostic impact of postoperative radiation in patients undergoing radical esophagectomy for pathologic lymph node positive esophageal cancer. Radiat Oncol 8:116 